\title{
Transmission Electron Microscopic Analysis of Geopolymer Made of Fused Slags
}

\author{
Yootaek Kim ${ }^{*}$ and Kyongwoo Lee \\ Department of Materials Engineering, Kyonggi University, Suwon, Republic of Korea 16227 \\ *Corresponding author
}

\begin{abstract}
The production of fused slag generated is continuously increasing and is expected to reach $\mathbf{5 0 , 0 0 0}$ tons per year as coal gasification facilities and waste treatment systems producing fused slag have been actively adopted recently in Korea. One of the prospective solutions is to make geopolymers with the slags because geopolymers are a cement substitute that can reduce the generation of carbon dioxide and have thus attracted increasing interest from recycling and eco-friendly construction industries because they provide sufficient mechanical strength for application in construction materials. Geopolymers made of fused slags with an alkali activator exhibited very high compressive strength compared with those of ordinary geopolymers, and their microscopic structures were analyzed by transmission electron microscopy (TEM) to confirm the formation of crystallites during the geopolymerization and to explain the relationship between the microstructure and mechanical property of the geopolymers.
\end{abstract}

Keywords-transmission electron microscope; geopolymer; fused slag; alkali-activator

\section{INTRODUCTION}

Environment-friendly construction materials, which produce less carbon dioxide resulting in the reduction of $\mathrm{CO}_{2}$ emissions have been much interested in many studies nowadays. Moreover, low-grade coal has become a major energy source as energy consumption increases because it is abundant and inexpensive. Recently, many integrated gasification combined cycle (IGCC) process facilities were built in Korea in accordance with the policy of energy diversification. The recycling of wastes such as fused slags produced from the IGCC process and municipal solid waste incinerator fly ash has also been performed to increase the recycling rate and protect the environment to catch up with the increasing social needs resulting from the rapid increase in the amount of fused slags from various fields $[1,2]$. One of the solutions is to use geopolymers, which are a type of inorganic and polymeric material and are a prospective alternative to ordinary Portland cement (OPC) [3, 4]. It has been reported that geopolymer-based concrete releases only $1 / 6$ of the $\mathrm{CO}_{2}$ emitted by the production of OPC $[5,6]$.

The geopolymerization reaction is exothermic and results in the formation of compact, amorphous to semi-crystalline solid materials. Therefore, geopolymers are inorganic polymers, which are macromolecules linked by covalent bonds that have a-Si-O-M-O- backbone, where $\mathrm{M}$ usually denotes aluminum [7-9]. It is well known that the $\mathrm{Si} / \mathrm{Al}$ ratio of geopolymer binders strongly affects the resulting properties
[10]. It is expected that the compressive strength of geopolymers should increase monotonically with the silica content because the strength of $\mathrm{Si}-\mathrm{O}-\mathrm{Si}$ bonds is higher than those of $\mathrm{Si}-\mathrm{O}-\mathrm{Al}$ and $\mathrm{Al}-\mathrm{O}-\mathrm{Al}$ bonds [11-12].

The fused slag used in this study was obtained from the fused slag (melted residues) after gasification processes using low-grade coal, which has a low carbon content. The other type of slag used in this study is called spent catalyst slag (SCS), which was produced as a by-product during the extraction of precious metals from spent catalysts.

Phase analyses of geopolymers using techniques including X-ray diffraction (XRD), infra-red (IR) spectroscopy, and Raman spectroscopy have been performed by many researchers; the phases among geopolymers, OPC, blast furnace slag, and alkali-activated slag have been compared, some of the peaks have been indexed, suggesting the existence of crystallites in the matrix of geopolymers [13-16]. Some papers have also suggested the existence of crystallites in the matrix of geopolymers based on scanning electron microscopy (SEM) and energy dispersive spectroscopy (EDS) analysis only [3, 17-19]. However, crystal structural analyses using electron diffraction patterns obtained from crystallites in the matrix of geopolymers have been rarely reported by other researchers [13]. Phase changes or new phases after hightemperature treatment of geopolymers have been reported; however, few researchers have reported the creation of crystalline phases during the geopolymerization process at low-temperature curing [20-22].

In this study, selected area diffraction (SAD) patterns from a geopolymer matrix were indexed, and it was also speculated that the mechanical property is related to the $\mathrm{Si} / \mathrm{Al}$ ratio as well as the existence of micro-crystallites in the geopolymer matrix.

\section{EXPERIMENTALS}

The $\mathrm{Si} / \mathrm{Al}$ ratio was controlled by mixing two fused slags with different compositions, as observed in Table 1. FS were obtained after the melting-gasification process during the combustion of urban municipal solid waste, and sewage sludge was obtained by feeding cooling water at room temperature. SCS was produced as a by-product during the extraction of precious metals from spent catalysts at high temperature. FS and SCS were milled for $2 \mathrm{~h}$ to obtain particles that were then passed through a 106 mesh sieve. The compositions in Table 1 were determined using X-ray fluorescence (XRF, SPECTRO 
2000). The FS and SCS were mainly composed of silica, alumina, and calcia but with different contents.

TABLE I. COMPOSITIONS (WT\%) OF THE FS AND SCS

\begin{tabular}{|c|c|c|}
\hline Oxide & FS & SCS \\
\hline $\mathbf{S i O}_{2}$ & 47.26 & 29.71 \\
\hline $\mathbf{A l}_{2} \mathbf{O}_{3}$ & 17.70 & 35.81 \\
\hline $\mathbf{F e}_{2} \mathbf{O}_{3}$ & 7.61 & 0.64 \\
\hline $\mathbf{C a O}$ & 11.83 & 22.66 \\
\hline $\mathbf{M g O}$ & 3.00 & 775 \\
\hline $\mathbf{N a}_{2} \mathbf{O}$ & 3.26 & 0.18 \\
\hline $\mathbf{K}_{2} \mathbf{O}$ & 1.50 & 0.34 \\
\hline $\mathbf{T i O}_{2}$ & 0.78 & 0.4 \\
\hline $\mathbf{Z r O}_{2}$ & - & 1.96 \\
\hline $\mathbf{P}_{2} \mathbf{O}_{5}$ & - & 0.5 \\
\hline $\mathbf{C r}_{2} \mathbf{O}_{3}$ & 1.40 & - \\
\hline $\mathbf{M n O}$ & - & - \\
\hline $\mathbf{S O} \mathbf{O}_{3}$ & 0.12 & - \\
\hline $\mathbf{S i} / \mathbf{A l}$ & 1.27 & 0.70 \\
\hline
\end{tabular}

XRD analyses of the two slags in Table 1 have been reported earlier [24]; the phases of both FS and SCS are completely amorphous; no particular peak and only background was observed, which is typical for XRD patterns from amorphous materials. SEM examination reveals that the particle size and shape of FS and SCS were similar, and the particle size distribution of each raw material was also similar [23]; it is well know that the particle size distribution is one of the main influencing factors on geopolymerization [24]. Therefore, the effect of the particle size distribution of raw materials on the compressive strength of geopolymers may be negligible.

TABLE II. FS/SCS MIXING RATIOS AND RESULTING SI/AL RATIOS OF THE GEOPOLYMERS.

\begin{tabular}{|c|c|}
\hline FS $:$ SCS & Si/Al ratio \\
\hline $100: 0$ & 29.71 \\
\hline $80: 20$ & 35.81 \\
\hline $60: 40$ & 0.64 \\
\hline $40: 60$ & 22.66 \\
\hline $20: 80$ & 775 \\
\hline $0: 100$ & 0.18 \\
\hline
\end{tabular}

The liquid/solid ratio was fixed at 0.15 . Pellets, $10 \mathrm{~mm}$ in both diameter and height, were prepared by compression molding at a pressure of $25 \mathrm{MPa}$ for $20 \mathrm{~s}$. For curing, the specimens were sealed in a polyethylene zipper bag to prevent the evaporation of moisture; the internal humidity was maintained at $99 \%$.

The compressive strength of the cylindrical geopolymer pellets was determined using a universal test machine (UTM$900 \mathrm{NH}$ Series, DAEKYUNG, Korea) at a crosshead speed of $5 \mathrm{~cm} / \mathrm{min}$. The phase analysis was performed using XRD (MiniFlex2, Rigaku, Japan), which was operated at $40 \mathrm{kV}$ and $40 \mathrm{~mA}$ using $\mathrm{Cu}-\mathrm{K}_{\alpha}$ radiation. The microstructure of the geopolymers was observed by SEM (S-4800, HITACHI, Japan) using secondary electrons and by TEM (JEM-3010, JEOL Japan). The specimens were coated with platinum before the SEM observations at an accelerating voltage of $5 \mathrm{kV}$. The TEM specimens were milled using an ion-miller (Quanta 3D FEG, FEI, USA) and mounted on a platinum grid.

\section{RESULTS AND DISCUSSION}

\section{A. XRD Analysis and Compressive Strength}

Figure 1 shows the XRD peaks from geopolymers with six different $\mathrm{Si} / \mathrm{Al}$ ratios after geopolymerization. C-S-H (calcium silicate hydrate), C-A-H (calcium aluminum hydrate), zeolite, and quartz peaks are identified. Some crystalline phases formed in all of the specimens from the completely amorphous phase after geopolymerization. The degree of crystallinity can hardly be determined by XRD analyses; however, it appears that the number of diffraction peaks and intensities increased with decreasing $\mathrm{Si} / \mathrm{Al}$ ratio. The $\mathrm{C}-\mathrm{A}-\mathrm{H}$ and zeolite peaks are almost disappeared at high $\mathrm{Si} / \mathrm{Al}$ ratio.

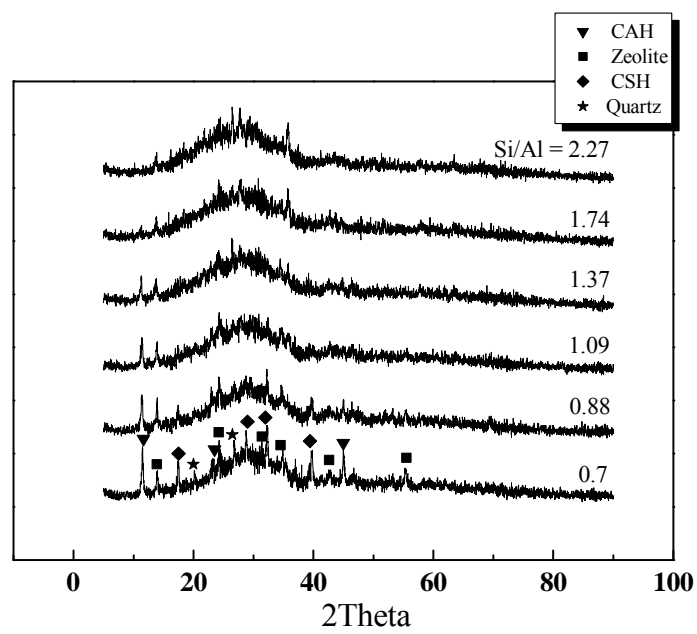

FIGURE I. XRD PATTERNS OF THE GEOPOLYMERS WITH SIX DIFFERENT SI/AL RATIOS AFTER GEOPOLYMERIZATION.

\section{B. Compressive Strength}

The compressive strength of all the specimens of this study is much higher than that of ordinary geopolymers made of metakaoline or related materials $[5,12]$. It should be noted that the specimens in this study were prepared using pressure molding (25 MPa for $20 \mathrm{~s}$ ), a low liquid/solid ratio (0.15 for solid/liquid), and a high alkali concentration (18 M), which may explain the relatively high compressive strength compared with that of ordinary geopolymers. However, investigating the effects of the $\mathrm{Si} / \mathrm{Al}$ ratio and of emerging new phase(s) after geopolymerization on the compressive strength of geopolymers under the above experimental conditions remains of interest.

The compressive strength during the early stage of curing ( 1 day and 7 days) was even slightly higher than that after a longer curing period of 28 days, although the difference was within $20 \mathrm{MPa}$. Hence, only a slight change in the 
compressive strength of the specimens was observed after 28 days of curing. Therefore, it can be concluded that the Si/Al ratio affects the compressive strength during the early stage of curing, whereas there is almost no effect on the compressive strength at the longer stage of curing.

\section{TEM Analysiss}

Figure 2(a) shows a typical bright-field (BF) image of the geopolymer matrix of the specimens with low $\mathrm{Si} / \mathrm{Al}$ ratios (0.7-1.5) after 28 days of aging. There are many small particles with sizes ranging from $10-30 \mathrm{~nm}$. It is well known that such small particles are not expected to form in an amorphous material. Moreover, it is even less expected to find these crystal-like particles in FS- and SCS-based geopolymers because these types of slag are melted and fused in a melting furnace at very high temperatures (above $1500^{\circ} \mathrm{C}$ ). The XRD analysis demonstrated that there were no crystalline phases in the as-received FS and SCS, and thus, the raw materials were amorphous [23].

It is deduced from the above discussion that the crystal-like particles present in Figure 2(a) may have precipitated or grown during the polymerization reaction of the geopolymer. It is also expected that these particles are crystallites with singlecrystal structures. Therefore, TEM measurements were performed to determine their crystallographic structure. Diffraction pattern analysis and corresponding images from the selected area diffraction (SAD) patterns are usually used to identify the crystallinity and orientation of inorganic specimens. The circle in Figure 2(a) indicates the position of the selected area diffraction aperture (SADA), which was used to obtain the SAD pattern presented in Figure 2(b). The size of SADA1 used to obtain the SAD patterns was $50 \mathrm{~nm}$. Based on the SAD pattern, it can be observed that several diffraction patterns from at least two different crystallites are overlapping, as evidenced by the faint ring-like diffraction patterns and extra-diffraction spots, which are normally observed in polycrystalline materials. The beam direction and the indexing of the spots are indicated in Figure 2(b). As observed from the analysis in Figure 2(b), the crystals were identified as C-S-H.

As observed in Figure 2(c), a lower magnification was employed to see a larger area and to find larger single crystals. A relatively large single-crystal-like particle can be observed in the center of Figure 2(c). This single-crystal-like particle was measured with SADA2, and the corresponding SAD pattern is presented in Figure 2(d). The diffraction pattern in Figure 2(d) is a typical SAD pattern for a single crystal, which has a perfect crystalline structure. Therefore, it is concluded that a single crystal with a mean particle size of approximately $80-100 \mathrm{~nm}$ as well as nano-crystallites with sizes of 10-30 nm grew or formed during the geopolymerization process. The beam direction and indexing of the spots are indicated in Figure 2(d). As observed based on the analysis of Figure 2(d), the crystals were identified as $\mathrm{Ca}(\mathrm{OH})_{2}$ crystals with a perfect single-crystal structure.
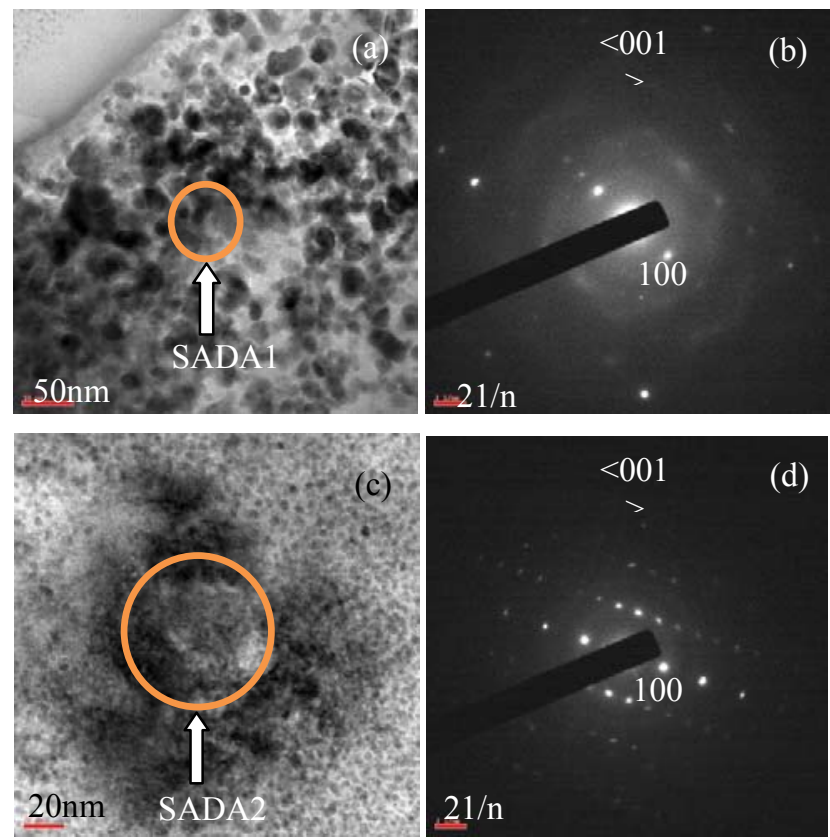

FIGURE II. TEM MICROGRAPHS AND SAD PATTERNS OF THE GEOPOLYMER WITH A SI/AL RATIO OF 1.74 AFTER 28 DAYS OF AGING. (A) A BF IMAGE WITH THE SAD APERTURE INDICATED BY THE ARROW. (B) THE CORRESPONDING SAD PATTERN FROM THE ENCIRCLED AREA LIMITED BY THE SADA1 IN (A). SAD WAS OBTAINED FROM AN AREA CONTAINING AT LEAST TWO CRYSTALLITES. (C) A LOWER MAGNIFICATION BF IMAGE, WHICH

IS NEAR THE AREA IN (A), AND (D) THE CORRESPONDING SAD PATTERN FROM THE ENCIRCLED AREA LIMITED BY SADA2 IN (C).

\section{CONCLUSIONS}

Geopolymers with six different $\mathrm{Si} / \mathrm{Al}$ ratios were investigated using TEM. The existence of micro-crystallites was confirmed by TEM observations along with SAD analyses. TEM images revealed crystallites with a mean particle size of $80-100 \mathrm{~nm}$ as well as nano-crystallites with sizes of 10-30 nm that had grown or formed during the geopolymerization process. It may be speculated that the formation of these crystals and crystallites may result in the high compressive strength of the geopolymers.

Indexing of SAD patterns obtained from geopolymers was performed and enabled the identification of the compositions and orientations of the crystallites. At least two types of crystals were present in the matrix of the geopolymer. C-S-H and $\mathrm{Ca}(\mathrm{OH})_{2}$ crystallites were identified by SAD indexing, indicating that the amorphous state of the $\mathrm{Ca}$ and $\mathrm{Si}$ composition resulted in the crystal form of $\mathrm{C}-\mathrm{S}-\mathrm{H}$ and $\mathrm{Ca}(\mathrm{OH})_{2}$ after the hydration process, and these crystallites were the intermediate state of the geopolymerization or carbonation process. C-A-H and quartz phases were not observed in the TEM and SAD analyses because these phases disappeared at high $\mathrm{Si} / \mathrm{Al}$ ratios, as observed in Figure 1. The existence of $\mathrm{Ca}(\mathrm{OH})_{2}$ crystallites implies that extra strength of the specimen is expected at longer aging times because of the formation of $\mathrm{CaCO}_{3}$ or $\mathrm{CSH}$ from $\mathrm{Ca}(\mathrm{OH})_{2}$ crystallites. The details of this mechanism will be investigated in future work. 


\section{ACKNOWLEDGMENT}

This work was supported by the New \& Renewable Energy Core Technology Program of the Korea Institute of Energy Technology Evaluation and Planning (KETEP), granted financial resource from the Ministry of Trade, Industry \& Energy, Republic of Korea. (No. 20153030050080)

\section{REFERENCES}

[1] Ferone, C., Colangelo, F., Messina, F., Santoro, L. and Cioffi, R., "Recycling of pre-washed municipal solid waste incinerator fly ash in the manufacturing of low temperature setting geopolymer materials," Materials, Vol. 6, pp. 3420-3437, 2013.

[2] Guo, X, Hu, W and Shi, H. "Microstructure and self-solidification /stabilization (S/S) of heavy metals of nano-modified CFA-MSWIFA composite geopolymers," Construction and Building Materials, Vol. 56, pp. 81-86, 2014.

[3] He, J., Zhang, J.H., Yu, Y.H. and Zhang, G.P., "The strength and microstructure of two geopolymers derived from metakaolin and red mud-fly ash admixture: A comparative study," Construction and Building Materials, Vol. 30, pp. 80-91, 2012.

[4] Habet, G., d'Espinose de Lacaillerie, J.B. and Roussel, N., "An environmental evaluation of geopolymer based concrete production: reviewing current research trends," Journal of Cleaner Production Vol. 19, No. 11, pp. 1229-1238, 2011.

[5] Duxson, P., Femandesz-Jimenez, A., Provis, J., Lukey, G., Palomo, A. and Van Deventer, J., "Geopolymer technology: the current state of the art,” Journal of Materials Science, Vol. 42, No. 9, pp. 2917-2933, 2007

[6] Duxson, P., Provis, J., Lukey, G. and Van Deventer, J., "The role of inorganic polymer technology in the development of 'green concrete' ,' Cement and Concrete Research, Vol. 37, No. 12, pp. 1590-1597, 2007.

[7] Davidovits, J., "99 Geopolymer International Conference Proceedings, edited by J. Davidovits, Geopolymer Institute," Saint Qunentin, 1999.

[8] Sakkas, K., Panias, D., Nomikos, P. and A. Sofianos, "Potassium based geopolymer for passive fire protection of concrete tunnels linings," Tunnelling and Underground Space Technology, Vol. 43, pp. 148-156, 2014.

[9] Davidovits, J., "Geopolymer '88, editied by J. Davidovits, J. Orlinsky," The Institute, Compiegne, 1988.

[10] Buchwald, A., Zellmann, H. and Kaps, C., "Condensation of aluminosilicate gels - model system for geopolymer binders," Journal of Non-Crystalline Solids, Vol. 357, pp. 1376-1382, 2011.

[11] Duxson, P., Provis, J., Lukey, G., Mallicoat, S., Kriven, W. and van Deventera, J., "Understanding the relationship between geopolymer composition, microstructure and mechanical properties," Colloids and Surfaces A, Vol. 269, pp. 47-58, 2005.

[12] de Jong, B.H.W.S. and Brown, G.E. "Polymerization of silicate and aluminate tetrahedra in glasses, melts, and aqueous solutions- $\mathrm{I}$. Electronic structure of $\mathrm{H}_{6} \mathrm{Si}_{2} \mathrm{O}_{7}, \mathrm{H}_{6} \mathrm{AlSiO}_{7}{ }^{1-}$, and $\mathrm{H}_{6} \mathrm{Al}_{2} \mathrm{O}_{7}{ }^{2-}$," Geochimica et Cosmochimica Acta, Vol. 44, No. 3, pp. 491-511, 1980.

[13] Xu, H. and Van Deventer, Jannie S. J., "Microstructural characterization of geopolymers synthesised from kaolinite /stilbite mixtures using XRD, MAS-NMR, SEM/EDX, TEM/EDX, and HREM," Cement and Concrete Research, Vol. 32, pp. 1705-1716, 2002.

[14] Lecomte, I., Henrist, C., Liegeois, M., Maseri, F., Rulmont, A. and Cloots, R., "(Micro)-structural comparison between geopolymers, alkaliactivated slag cement and Portland cement," Journal of the European Ceramic Society, Vol. 26, pp. 3789-3797, 2006.

[15] Meral, C., Benmore, C. and Monteiro, P., "The study of disorder and nanocrystallinity in $\mathrm{C}-\mathrm{S}-\mathrm{H}$, supplementary cementitious materials and geopolymers using pair distribution function analysis," Cement and Concrete Research, Vol. 41, pp. 696-710, 2011.

[16] Criado, M., Fernández-Jiménez, A., de la Torre, A., Aranda, M. and Palomo, A., "An XRD study of the effect of the $\mathrm{SiO}_{2} / \mathrm{Na}_{2} \mathrm{O}$ ratio on the alkali activation of fly ash," Cement and Concrete Research, Vol. 37, pp. 671-679, 2007.
[17] Xie, Z. and Xi, Y., "Hardening mechanisms of an alkaline-activated class F fly ash," Cement and Concrete Research, Vol. 31, pp. 1245-1249, 2011.

[18] Zhang, Z., Wang, H., Provis, J., Bullen, F., Reid, A. and Zhu, Y., "Quantitative kinetic and structural analysis of geopolymers. Part 1. The activation of metakaolin with sodium hydroxide," Thermochimica Acta, Vol. 539, pp. 23-33, 2012.

[19] Lee, W. and Van Deventer, J., "The interface between natural siliceous aggregates and geopolymers," Cement and Concrete Research, Vol. 34, pp. 195-206, 2004.

[20] Kuenzel, C., Grover, L., Vandeperre, L., Boccaccini, A. and Cheeseman, C., "Production of nepheline/quartz ceramics from geopolymer mortars," Journal of the European Ceramic Society, Vol. 33, pp. 251-258, 2013.

[21] Barbosa, V. and MacKenzie, K., "Synthesis and thermal behaviour of potassium sialate geopolymers," Materials Letters, Vol. 57, pp. $1477-$ 1482, 2003.

[22] Liu, L., Cui, X., He, Y., Liu, S. and Gong, S., "The phase evolution of phosphoric acid-based geopolymers at elevated temperatures," Materials Letters, Vol. 66, pp. 10-12, 2012.

[23] Kim, Y. and Choi, J., "Performance Evaluation of Compressed Geopolymer Using Fused Slag and Spent Catalyst Slag Employing Microscopy," AES Technical Reviews International Journal, Vol. 1, pp. 29-40, 2014.

[24] Van Jaarsveld, J., Van Deventer, J. and Lukey, G., "The characterisation of source materials in fly ash-based geopolymers," Materials Letters, Vol. 57, pp. 1272-1280, 2003. 